\title{
Preface for the Issue of Topics in Catalysis Dedicated to the Memory of Professor Frank S. Stone
}

\author{
The Nineteenth Rideal Conference on Chemisorption and Catalysis Harwell Catalysis Hub Held \\ at Cosener's House, Abingdon, 26-28 March 2018
}

\author{
Martyn V. Twigg ${ }^{1}$
}

Published online: 8 November 2019

(c) Springer Science+Business Media, LLC, part of Springer Nature 2019

The Rideal Conferences are named in honour of Sir Eric Rideal who did much to lay the foundations of modern chemisorption science and heterogeneous catalysis. The Conference series had their origin in 1962 when Professor Charles Kemball organised a symposium at Queen's University in Belfast, Northern Ireland during the week before Easter to honour his former Cambridge $\mathrm{PhD}$ supervisor. At that time Eric Rideal was at Imperial College where he had been since retiring from the Chair of Physical Chemistry at King's College London in 1955. The title of the symposium was "Chemisorption and Catalysis" and it was very successful with some 80 invited eminent delegates entering into extended friendly discussion and debate about the latest research results in areas largely pioneered by Eric Rideal. A second conference along the same lines was organised 3 years later in 1965 by Professor Frank Stone at the University of Bristol, and 3 years after that in 1968 another of Rideal's former Cambridge PhD students, Professor Dan Eley, organised a similar conference at the University of Nottingham and it was there the name "Rideal Conference" was adopted. Further Rideal Conferences have been held in the week just before Easter whenever possible every 3 years.

Professor Kemball's symposium was in Northern Ireland and most of the Conferences that followed were held in mainland UK with the exceptions of one at University College Dublin in 1986 organised by Professor John Clarke. Sir Eric Rideal obtained his PhD at the University of Bonn in Germany and fittingly the Eighteenth Conference was held at The Fritz-Haber-Institut der Max-Planck-Gesellschaft in

Martyn V. Twigg

marsarbooks@yahoo.co.uk

1 Twigg Scientific \& Technical Ltd, Caxton, Cambridge CB23 3PQ, UK
Berlin in 2015 which was a particularly successful event organised by Professor Hans-Joachim Freund.

The present Rideal Conference, the nineteenth in the series, was again in the UK and it was hosted by the Harwell Catalysis Hub and held at Cosener's House conference centre in the old town of Abingdon in Oxfordshire. The very topical theme of the conference was "Designing new catalytic processes to address global challenges" and the senior local organiser of the Conference was Professor Richard Catlow with superb support from Josie Goodall and Corinne Anyika who worked tirelessly both before and during the actual Conference (Fig. 1).

On the morning of the first day there was a tour of the Harwell Research Campus to see some of the cutting edge facilities available there that are particularly relevant to the study of catalysts and catalysis. These included the Diamond Light Source (the national synchrotron science facility), the ISIS facility that produces beams of pulsed neutrons and muons from the impact of high energy protons with targets, and the Central Laser Facility with a range of state-of-the-art laser technology and there was also a general overview of the entire research complex.

The afternoon began with a short oral obituary by the present author for Professor Frank Stone who had passed away 3 weeks earlier and was very much involved with the Rideal Conferences since their inception 56 years earlier. This was followed by a minutes silence in his memory and this special issue of Topics in Catalysis is dedicated to Professor Frank Stone. One of Professor Stone's first PhD students at the University of Bristol was Dr. Ronald M. Dell and he was extremely helpful in providing information about the time during his postgraduate research for inclusion in the paper in this issue of Topics in Catalysis entitled "Professor Frank S. Stone: The Life of a Solid State and Catalytic Chemist". Fittingly the second paper about the development 


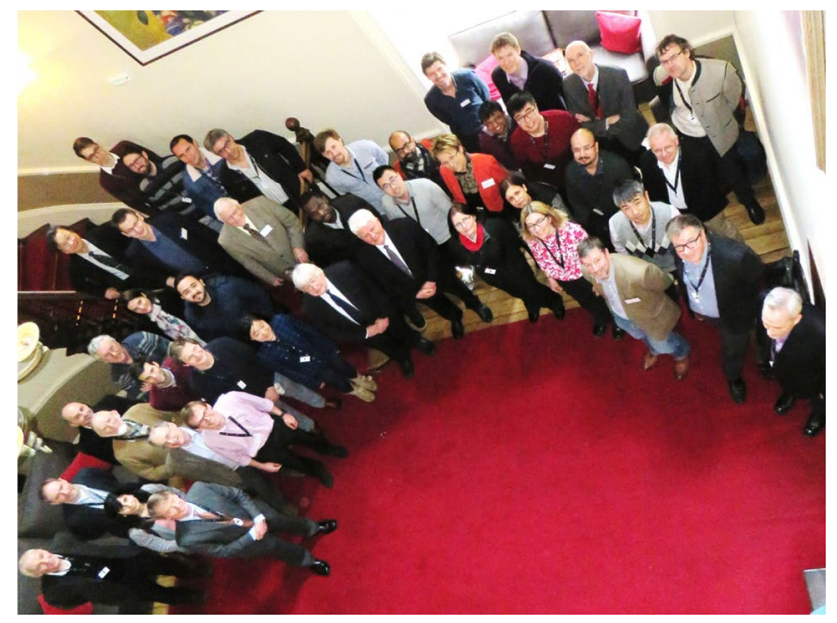

Fig. 1 Delegates at the nineteenth Rideal Conference organised by the Harwell Catalysis Hub held at the Cosener's House Conference Centre, Abingdon, Oxfordshire, 26-28 March 2018

and scale-up of industrial nitrous oxide abatement catalyst is co-authored by one of Professor Stone's last PhD students at the University of Bath Dr David Weller so nicely circling Stone's career. The subsequent papers in this issue follow the order in which the authors made presentations at the Rideal Conference.

The first technical session entitled "Sustainable catalytic reaction engineering" was chaired by Professor Chris Hardacre (University of Manchester) and had four contributions: "Kinetics as a tool for catalyst, reactor and process design" by Professor Joris Thybaut (University of Ghent), "Information-rich experimentation via microreactor technology" by Professor Asterios Gavriilidis (University College London), "Novel catalytic distillation processes for a sustainable chemical industry" by Professor Anton Kiss (University of Manchester/University of Twente), and "Exploiting the 'chemical memory' of non-stoichiometric materials to create new processes" by Professor Ian Metcalfe (University of Newcastle). The first day finished with a busy poster session with three prizes for the best posters donated by the Royal Society of Chemistry (journal subscriptions) and a voucher donated by Finden Ltd. The winners were Dr. Santhosh Kumar Matam, Mr. Charan Kuppili and Dr. Ines Lezcano-Gonzalez.

The first short session of the second day had the title "Designing new nanomaterials as effective catalysts" and was chaired by Professor Gianfranco Pacchioni (Università Milano-Bicocca). There were two contributions: "New nano-structured complex metal oxides of group V and VI elements as solid-state catalysts" by Professor Wataru Ueda (Kanagawa University), and "Real time observation of the evolution of catalyst nanostructure" by Professor Andy Beale (University College London), The second session in the morning was chaired by Professor Adrian Mulholland (University of Bristol) also had two contributions: "Low temperature hydrogen production from ammonia" by Dr. Laura Torente (University of Cambridge) and "Preventing catalyst deactivation during the continuous conversion of sugars to chemicals" by Dr. Ceri Hammond (Cardiff University),

The third session of the second day was entitled "Computational methods for catalysts design" and was chaired by Professor Richard Catlow (University College London), There were four contributions: "Design of active catalysts from first principles: concepts, examples, and perspectives" by Professor Gianfranco Pacchioni (Università Milano-Bicocca), "Balancing reductionist and systems approaches in computational catalysis: questions of accuracy and adequacy" by Professor Evgeny Pidko (Delft University of Technology/ITMO University), "Multiscale modelling for biocatalysis" by Professor Adrian Mulholland (University of Bristol) and "Role of conformational dynamics in the evolution of enzyme function" by Dr. Sílvia Osuna (University of Girona).

The final session of the second day was entitled "Integrated chemo/bio-catalysis" and chaired by Professor Nick Turner (University of Manchester) had four contributions: "Reaction engineering challenges in biological catalysis" by Professor John Woodley (Technical University of Denmark), "Making hard things look easy" by Professor James Naismith (Research Complex at Harwell), "Biocatalytic access to chiral amines and $\mathrm{C}-\mathrm{C}$ bond formation" by Professor Wolfgang Kroutil (University of Graz), and "Integration of engineered enzymes into new synthetic and biosynthetic pathways" by Professor Jason Micklefield (University of Manchester).

A particularly enjoyable Conference Dinner took place on the evening of the second day of the Conference in the Barn Restaurant in the Crown and Thistle Hotel in Abingdon. Poster prizes were presented to the three winners and there was a short talk about the influence Sir Eric Rideal had on the early development of catalysis highlighting the work he did at University College London during the First World War following the association his father had there.

The final session on the third day was entitled "In situ studies of catalysis" and was chaired by Professor Martyn Twigg (TST Ltd) and had four contributions: "Catalysts caught in the act-what in situ spectroscopy can tell us about active sites and mechanisms" by Professor Angelika Brückner (Leibniz Institute for Catalysis, Rostock), “About active sites and interfaces in catalysis" by Professor Jeroen van Bokhoven (Paul Scherrer Institute, Switzerland), "Observing single-site catalysis during reaction" by Dr. Simon Kondrat (Loughborough University) and "Tracking reaction intermediates in sustainable catalytic processes 
with in situ/operando spectroscopy" by Dr. Gareth Whiting (Utrecht University).

The Conference was attended by more than 60 scientists and engineers involved with traditional heterogeneous catalysis, homogeneous catalysis and enzyme catalysis that bridged the disciplines of chemistry engineering and biology. Delegates came from a number of countries including: Belgium, Germany, Italy, Greece, Japan, The Netherlands, Switzerland and America as well as the UK. After each session there was a period of discussion that continued during breaks and meals. Following the last session there were some closing comments before delegates had lunch and dispersed. In conclusion this was a very successful Conference with stimulating presentations and extensive open discussions throughout. The senior local organiser of the Conference was Professor Richard Catlow and the huge amount of work done by Josie Goodall and Corinne Anyika ensured the Conference ran smoothly and efficiently. Thanks are also due the helpful staff at the Harwell Catalysis Hub, the Cosener's
House Conference Centre and the Barn Restaurant in the Crown and Thistle Hotel in Abingdon and also to the sponsors: The UK Catalysis Hub, Finden Ltd, Johnson Matthey Plc, The Royal Society of Chemistry, Springer and Twigg Scientific and Technical Ltd.

During the final stages of preparation of this issue of Topics in Catalysis there was the sad news of the death of Professor Michel Che. He was a good friend to many who have attended Rideal Conferences and the global catalysis community as a whole and it was therefore very appropriate to include in this issue an obituary by Sir John Meurig Thomas that succinctly details the life of Michel Che.

Publisher's Note Springer Nature remains neutral with regard to jurisdictional claims in published maps and institutional affiliations 